\title{
Excess mortality related to seasonal influenza and extreme temperatures in Denmark, 1994-2010
}

\author{
Jens Nielsen*, Anne Mazick, Steffen Glismann and Kåre Mølbak
}

\begin{abstract}
Background: In temperate zones, all-cause mortality exhibits a marked seasonality, and one of the main causes of winter excess mortality is influenza. There is a tradition of using statistical models based on mortality from respiratory illnesses (Pneumonia and Influenza: PI) or all-cause mortality for estimating the number of deaths related to influenza. Different authors have applied different estimation methodologies. We estimated mortality related to influenza and periods with extreme temperatures in Denmark over the seasons 1994/95 to 2009/10.

Methods: We applied a multivariable time-series model with all-cause mortality as outcome, activity of influenzalike illness (ILI) and excess temperatures as explanatory variables, controlling for trend, season, age, and gender. Two estimates of excess mortality related to influenza were obtained: (1) ILI-attributable mortality modelled directly on ILI-activity, and (2) influenza-associated mortality based on an influenza-index, designed to mimic the influenza transmission.

Results: The median ILI-attributable mortality per 100,000 population was 35 (range 6 to 100) per season which corresponds to findings from comparable countries. Overall, $88 \%$ of these deaths occurred among persons $\geq 65$ years of age. The median influenza-associated mortality per 100,000 population was 26 (range 0 to 73), slightly higher than estimates based on pneumonia and influenza cause-specific mortality as estimated from other countries. Further, there was a tendency of declining mortality over the years. The influenza $A(H 3 N 2)$ seasons of 1995/96 and 1998/99 stood out with a high mortality, whereas the A(H3N2) 2005/6 season and the 2009 A(H1N1) influenza pandemic had none or only modest impact on mortality. Variations in mortality were also related to extreme temperatures: cold winters periods and hot summers periods were associated with excess mortality.

Conclusion: It is doable to model influenza-related mortality based on data on all-cause mortality and ILI, data that are easily obtainable in many countries and less subject to bias and subjective interpretation than cause-of-death data. Further work is needed to understand the variations in mortality observed across seasons and in particular the impact of vaccination against influenza.
\end{abstract}

Keywords: influenza, mortality, temperature, seasonality

\section{Background}

In temperate zones, all-cause mortality exhibits a marked seasonality with the highest number of deaths in the winter and a lower number in the summer period. The reasons for this pattern are complex and not completely understood. Many factors may contribute, including increased rates of acute respiratory tract infections and death from cardio-vascular diseases in the winter months, periods with extreme temperature, and possibly mental

\footnotetext{
* Correspondence: nls@ssi.dk
Statens Serum Institut, Department of Epidemiology, Artillerivej 5, DK2300

* Correspondence: nls@ssi.dk
Statens Serum Institut, Department of Epidemiology, Artillerivej 5, DK2300 Copenhagen, Denmark
}

and physiological effects (e.g. D-vitamin) related to daylight as well as social and psychological factors related to Christmas and New Year holidays [1]. However, it is well recognised that one of the main causes of winter excess mortality is influenza.

There is a long tradition of using statistical models based on mortality from respiratory illnesses (Pneumonia and Influenza: PI) or all-cause mortality for estimating the number of deaths related to influenza. Different authors have applied different estimation methodologies. The most commonly used methodology, often called Serflings method, estimate the expected mortality without influenza 
based on either predefined periods with no or ignorable influenza activity [2,3] or dynamically defined periods with no influenza activity classified according to influenza activity recorded under a certain level e.g. 95\% confidence limit; data on influenza activity have been defined by influenza specific mortality [4-7], or Influenza Like Illness (ILI) reported from networks of sentinel practices [8-10] or reported as surveillance counts for laboratory virus-positive specimens [11,7]. Hence, periods with influenza-attributable mortality may vary from season to season according to each season's influenza activity. Excess mortality attributable to influenza is then calculated as the observed minus the modelled expected mortality without influenza as estimated from periods without influenza activity. Others has extended the estimation of the noinfluenza expected mortality to exclude impact of other respiratory and circulatory diseases, like infections from Respiratory Syncytial Virus (RSV), by controlling for presence of these in the estimation of the expected mortality in the absence of influenza $[9,11,12]$. Instead of excluding periods with influenza activity from the estimation of the no-influenza expected mortality, these periods may be down-weighted [13]. Alternatively, influenza activity can be included directly as a parameter in a multivariable time-series model, then often using an identity-link, including influenza activity, trend and seasonal variation as independent variables $[14,3,11,15]$. Thus, in this latter approach excess mortality is determined directly from data on influenza and not as a residual difference.

Ambient temperature may also play a role in the seasonal variation of mortality [14,16-19], but this is often not included in assessment of influenza-related mortality.

The aim of the present study was to describe mortality associated to influenza and periods with extreme temperatures in Denmark over the seasons 1994/95 to 2009/10.

\section{Materials and methods}

To investigate the impact of influenza and extreme temperatures on mortality we specified and applied a multivariable time-series model with all-cause mortality as outcome, influenza activity and excess temperatures as explanatory variables, and controlled for trend, season, age, and gender.

\section{Data sources}

Data for the analyses were obtained from the following sources:

Individual notifications of deaths were obtained from the Danish civil registry system by the Department of Epidemiology, Statens Serum Institut (SSI), in the form of daily electronic notifications of all deaths.

The sentinel influenza surveillance system based on primary health care consultations was established in 1994 as a voluntary reporting system of general practitioners providing weekly reports on the total number of consultations and age-specific numbers of Influenza-Like-Illness (ILI) consultations to the Department of Epidemiology, Statens Serum Institut (SSI). This system is usually discontinued in the summer period between week 20 and 40, but in 2009 data were collected throughout the year.

Data on daily temperatures registered at Danish weather stations was downloaded from the National Oceanic and Atmospheric Administration Online Climate Data Directory [20]. Mean over daily temperatures from all weather stations was used as the overall Danish temperature for that day. Weekly temperatures were calculated as the mean over the week, as was the weekly minimum and maximum temperatures. Using the mean weekly temperatures, we estimated the expected weekly temperature in a General-Linear-Model with a sine seasonal variation (Figure 1). Weeks with extreme temperatures was defined by a threshold-linear model [21]. Warm weeks were defined as weeks with weekly minimum temperature > expected weekly temperature; cold weeks as weekly maximum temperature < expected weekly temperature and the effect as the linear difference between observed and minimum respectively maximum weekly temperature.

Size of the Danish population by age and gender on the $1^{\text {st }}$ of January every year was downloaded from Statistics Denmark [22] (Table 1). The weekly sizes of the age group and gender specific populations were achieved by linear interpolation.

\section{Analyses}

In our primary analysis, termed ILI-attributable mortality, we fitted a model with the weekly all cause number of death as outcome and ILI-activity and extreme temperatures as independent variables and adjusted for trend, seasonal variation, age and gender.

Influenza circulates simultaneously with other respiratory tract infections that may have been reported as ILI, especially in autumn and spring, i.e. in the beginning and end of the influenza season. To get an indication of the part of ILI associated with mortality associated with influenza we did a sub-analysis, where we reduced ILI in the beginning and end of the period with activity; based on the assumption that the major part of ILI will be influenza at the peak whereas influenza will not be a major contributor to ILI when ILI is low. This analysis was termed influenza-associated mortality.

\section{Statistical analyses}

To estimate the association between weekly mortality, and influenza activity and extreme temperatures for the seasons $1994 / 5$ to $2009 / 10$ (week 27, 1994 to week 26, 2010), we used a multivariable time-series model with calendar week (wk) as underlying time unit, stratified by 


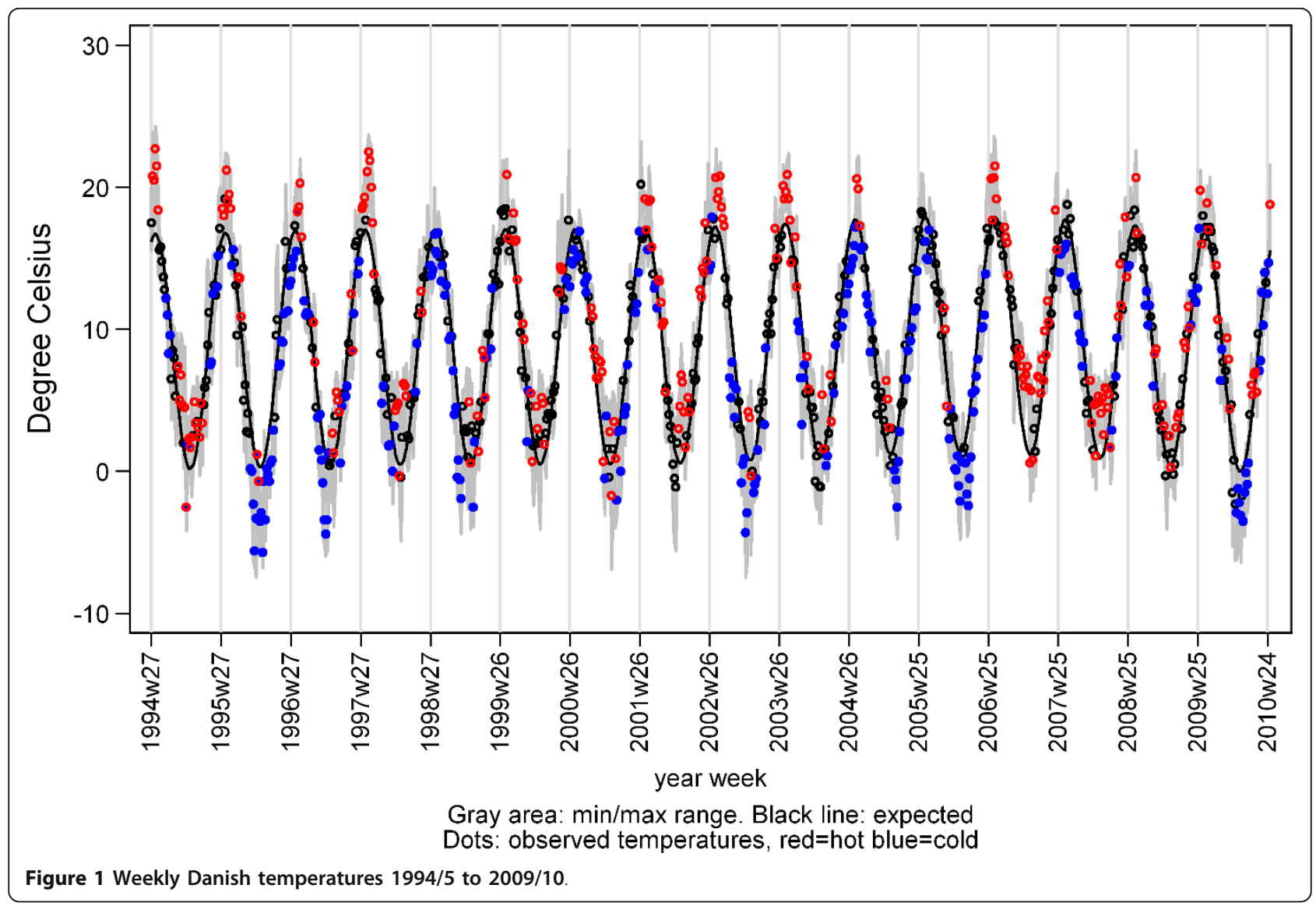

Table 1 The Danish population and dominating influenza virus, by season

\begin{tabular}{|c|c|c|c|c|c|c|}
\hline \multirow[t]{2}{*}{ Season $^{1}$} & \multirow{2}{*}{$\begin{array}{c}\text { Dominant } \\
\text { virus }\end{array}$} & \multicolumn{5}{|c|}{ Population $(100,000)$} \\
\hline & & All ages & $0-4$ years & 5-14 years & $15-64$ years & Aged 65 \\
\hline $1994 / 95$ & $\mathrm{H} 3 \mathrm{~N} 2$ & 52.18 & 3.35 & 5.67 & 35.17 & 7.99 \\
\hline $1995 / 96$ & $\mathrm{H} 3 \mathrm{~N} 2$ & 52.50 & 3.43 & 5.77 & 35.35 & 7.96 \\
\hline $1996 / 97$ & $\mathrm{H} 3 \mathrm{~N} 2$ & 52.74 & 3.46 & 5.90 & 35.45 & 7.93 \\
\hline $1997 / 98$ & $\mathrm{H} 3 \mathrm{~N}_{2}$ & 52.95 & 3.46 & 6.06 & 35.51 & 7.92 \\
\hline 1998/99 & $\mathrm{H} 3 \mathrm{~N} 2$ & 53.13 & 3.44 & 6.23 & 35.55 & 7.91 \\
\hline $1999 / 00$ & $\mathrm{H} 3 \mathrm{~N} 2$ & 53.30 & 3.41 & 6.40 & 35.59 & 7.91 \\
\hline $2000 / 01$ & $\mathrm{H} 1 \mathrm{~N} 1$ & 53.49 & 3.38 & 6.56 & 35.63 & 7.92 \\
\hline $2001 / 02$ & $\mathrm{H} 3 \mathrm{~N} 2$ & 53.68 & 3.35 & 6.69 & 35.68 & 7.95 \\
\hline 2002/03 & $\mathrm{H} 3 \mathrm{~N} 2$ & 53.83 & 3.32 & 6.80 & 35.72 & 7.99 \\
\hline $2003 / 04$ & $\mathrm{H} 3 \mathrm{~N} 2$ & 53.97 & 3.30 & 6.87 & 35.76 & 8.05 \\
\hline $2004 / 05$ & $\mathrm{H} 3 \mathrm{~N} 2$ & 54.12 & 3.28 & 6.90 & 35.81 & 8.13 \\
\hline $2005 / 06$ & $\mathrm{H} 3 \mathrm{~N} 2$ & 54.28 & 3.25 & 6.90 & 35.89 & 8.23 \\
\hline 2006/07 & $\mathrm{H} 3 \mathrm{~N} 2$ & 54.48 & 3.25 & 6.89 & 35.99 & 8.36 \\
\hline 2007/08 & H1N1 & 54.75 & 3.26 & 6.84 & 35.12 & 8.53 \\
\hline 2008/09 & $\mathrm{H} 3 \mathrm{~N} 2$ & 55.09 & 3.27 & 6.81 & 36.26 & 8.76 \\
\hline $2009 / 10$ & $\mathrm{H} 1 \mathrm{~N} 1^{2}$ & 55.35 & 3.26 & 6.75 & 36.30 & 9.04 \\
\hline
\end{tabular}

1) Season: week 27 to week 26 the following year. 2) Pandemic influenza A(H1N1) 2009/10 
age groups $(\mathrm{a}=0,1-4,5-14,15-44,45-64,65-74,75-84$, $85+$ years) and gender (g):

$$
\mathrm{E}\left(\mathrm{MR}_{\mathrm{a}, \mathrm{g}, \mathrm{wk}}\right)=\mathrm{E}\left(\mathrm{D}_{\mathrm{a}, \mathrm{g}, \mathrm{wk}} / \mathrm{N}_{\mathrm{a}, \mathrm{g}, \mathrm{wk}}\right)=\mathrm{E}\left(\mathrm{D}_{\mathrm{a}, \mathrm{g}, \mathrm{wk}}\right) / \mathrm{N}_{\mathrm{a}, \mathrm{g}, \mathrm{wk}}
$$

where MR is the Mortality Rate, D number of allcause deaths and $\mathrm{N}$ is the none-stochastic size of the population.

We used an additive Poisson regression model (link = id) with 1 /population-size as offset parameter and allowing for overdispersion. For each age group and gender, the model for $E(D)$ could formally be described as (omitting regression constants and parameters to be estimated):

$$
\begin{aligned}
& \mathrm{E}(\mathrm{D})=\text { spline }(\mathrm{wk})+ \\
& \sin (2 \pi(365.25 / 7) * w \mathrm{k})+\cos (2 \pi(365.25 / 7) * w \mathrm{k})+ \\
& \sin (4 \pi(365.25 / 7) * w k)+\cos (4 \pi(365.25 / 7) * w k)+ \\
& \sum_{\mathrm{s}} \sum_{\mathrm{wk}} \mathrm{IA}+\mathrm{wc}_{\mathrm{wk}}+\mathrm{ww}_{\mathrm{wk}}+\mathrm{sc}_{\mathrm{wk}}+\mathrm{sw}_{\mathrm{wk}}+ \\
& \sum \sum_{\mathrm{wk}-1} \mathrm{IA}+\mathrm{wc}_{\mathrm{wk}-1}+\mathrm{ww}_{\mathrm{wk}-1}+\mathrm{sc}_{\mathrm{wk}-1}+\mathrm{sw}_{\mathrm{wk}-1}+\sum \text { epi }
\end{aligned}
$$

where the terms spline(wk) and the sine and cosine terms express the baseline with trend and seasonality. Trend was included as a cubic spline, and both a yearly and half-yearly seasonal cycles were included as sines and cosines. Impact of influenza activity (IA) may be heterogeneous between seasons [23]. Hence, IA was included separately for each season s (season: week 27 to week 26 the following year): $\sum_{\mathrm{s}} \sum_{\mathrm{wk}}$ IA. In the primary analysis IA was expressed as proportion of weekly ILIconsultations. Impacts of extreme temperatures were separated in weeks with extreme summer or winter temperatures, and include as the four variables: $\mathrm{wc}=$ winter cold, $\mathrm{ww}=$ winter warm, $\mathrm{sc}=$ summer cold and $\mathrm{sw}=$ summer warm (Figure 1). Further, deaths may be delayed relative to when IA was registered at a consultation or relative to when the temperature was extreme. Therefore, IA and extreme temperature event from the preceding week were also included. Finally, to compensate major unexplained peaks (outliers), residuals greater than 1.5 standard deviations, lasting 3 week or more and not explained by IA or extreme temperatures were included as artificial epidemic-parameters to compensate these ( epi).

In order to obtain a more conservative estimation of influenza-associated mortality (rather than ILI), we applied an influenza-index to express influenza activity (IA), created by reducing the ILI consultation percentage for each season. This was done by multiplying the ILI consultation percentage in a specific season with a normal distribution, with mean and standard derivation as for the ILI percentage over the same season. This reduces the ILI percentage in the beginning and end of the season, and maintains the ILI percentage at the height of the season (Figure 2).
In the final model only trend and seasonal yearly or half-yearly cycles were included if they contributed on a $5 \%$ level $(p<0.05)$. Sensitivity to the temperature thresholds was investigated by varying the thresholds. Results are reported for the age groups 0-4, 5-14, 15-64 and $65+$ years of age and for both sexes together. Hence, the results were adjusted for heterogeneities in pattern and variations between ages and genders. All analyses were done using Stata $11 \mathrm{MP}$.

\section{Results}

The model fitted well in all age and gender strata (examined on deviances [24]), and there were no indications of either heteroskedasticity or residual autocorrelation (examined in correlograms). The results of the model are shown in Figure 3 for age groups and gender.

We found mortality to be associated with both ILIactivity and extreme temperatures (Figure 4).

The model included a baseline with both a yearly seasonal cycle and a half-yearly cycle, and the half-yearly cycle contributed on a $5 \%$ level in most strata. However, this was not due to a summer peaks; the half-year cycle created a seasonal pattern where the total seasonal cycle reaches its maximum earlier than for a symmetric yearly cycle, and as a consequence the decline became prolonged (baseline in Figure 4), corresponding more to the appearance of slightly asymmetric "epidemic curves" including a long right tail.

\section{ILI-attributable mortality}

Over the seasons $1994 / 5$ to $2009 / 10$ the total median number of excess deaths per season attributable to ILI was 1879 (range: 306-5251) and the median mortality rate (MR) per 100,000 population was 35.4 (range: 5.6-100.0), table 2. Most of the ILI associated deaths per year was among elderly $\geq 65$ years (median 87.9\%) and adults 15-64 years (median $11.4 \%$ ). There were nearly no ILI associated excess deaths among children (median 4 deaths for 0-4 years and -1 for $5-14$ years of age), table 2 .

Among adults, 15-64 years, there was an estimated annual number of ILI-associated deaths of 286 (range: -185 to 531 ) and the MR per 100,000 was 8.0 (range: -5.3 to 15.0 ). Among persons aged 65 the median number of deaths was 1738 (range: 365 to 4723) corresponding to a MR per 100,000 of 206.7 (range: 44.4 to 593.6). All estimates were adjusted for variations over age and between genders.

\section{Influenza-associated mortality}

Not all reported ILI-cases were influenza. Hence, we reduced the ILI consultation percentage according to a pattern that reflected influenza-transmission (Figure 3). Compared to the total ILI-attributable number of deaths, this reduced the median total number of excess deaths with 


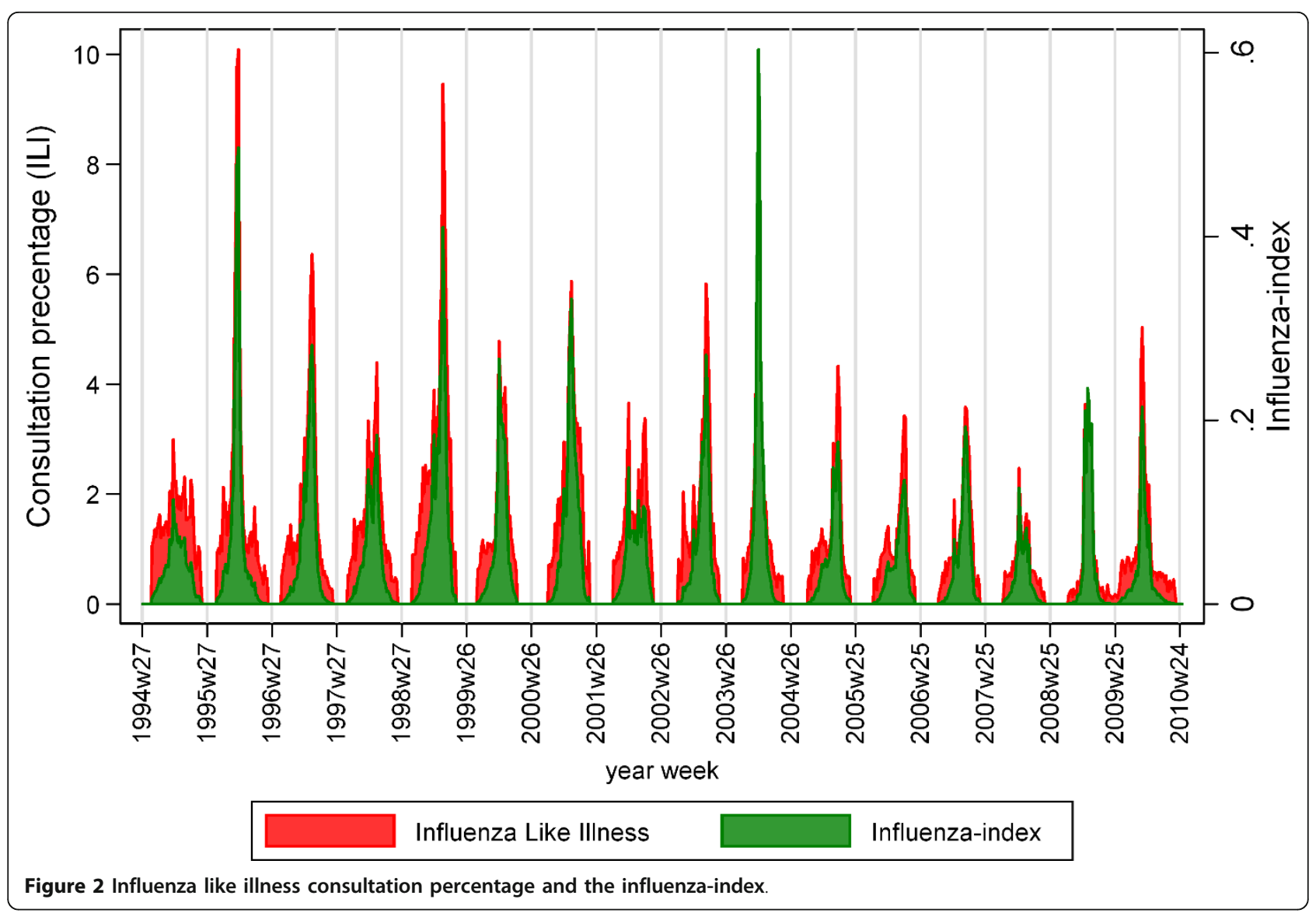

around $25 \%$ to 1420 (range: -8 to 3810 ) per season per 100,000 , and MR to 26.4 (range: -0.1 to 72.6 ) (Table 3). Overall, we estimated that $82.0 \%$ of the influenza-associated deaths were among elderly aged 65 years.

\section{Temperature associated mortality}

With our definition of a week having an extreme temperature, $38.5 \%$ of the weeks experienced extreme temperature (warm: $18.7 \%$, cold: $19.8 \%$ ) with a median extreme temperature of 1.4 (range: 0.3-4.1) degrees; warm: 1.5 (range: 0.4-4.1) degrees, cold: 1.3 (range: 0.33.2) degrees. Increasing the thresholds (minimum and maximum weekly temperatures) with up to 1 degree did not change the results substantially. Increasing the thresholds further reduced weeks with extreme temperatures seriously and therefore affected the results.

A yearly median of 39 deaths (range: -162 to 273) could be attributed to extreme ambient temperature, this corresponded to a MR per 100,000 of 0.7 (range: -3.0 to 5.2 ). These estimates were adjusted for variations over age and between genders (Table 4). The impact of extreme temperatures on mortality varied between benign (life saving) and malign (increased mortality) effects over the seasons, except among adults (15-64 years of age) where only malign effects of extreme temperatures were estimated. Further, a summer and winter differentiation in the impact of warm and cold temperatures was observed, with a benign effect of extreme cold during summer and the opposite in winter. For extreme warm temperatures it was the other way around (Table 5).

\section{Discussion}

Over the seasons $1994 / 5$ to $2009 / 10$ we found a median all-cause mortality rate of 35.4 (range: $5.6-100.0$ ) per season per 100,000 attributable to ILI for all ages and all inhabitants in Denmark, adjusted for trend, seasonality, extreme temperatures and heterogeneities between age groups and genders. Most of the mortality attributable to influenza was among the elderly (88\%). In the younger age groups $(<65)$ there were seasons with an estimated benign impact of circulating influenza (negative mortality rates). This might have been due to few deaths and as a consequence low statistical power. However, some of the negative estimates had narrow confidence intervals below zero and cannot be ignored. We believe the benign impact of circulating influenza in the population is due to changes in 


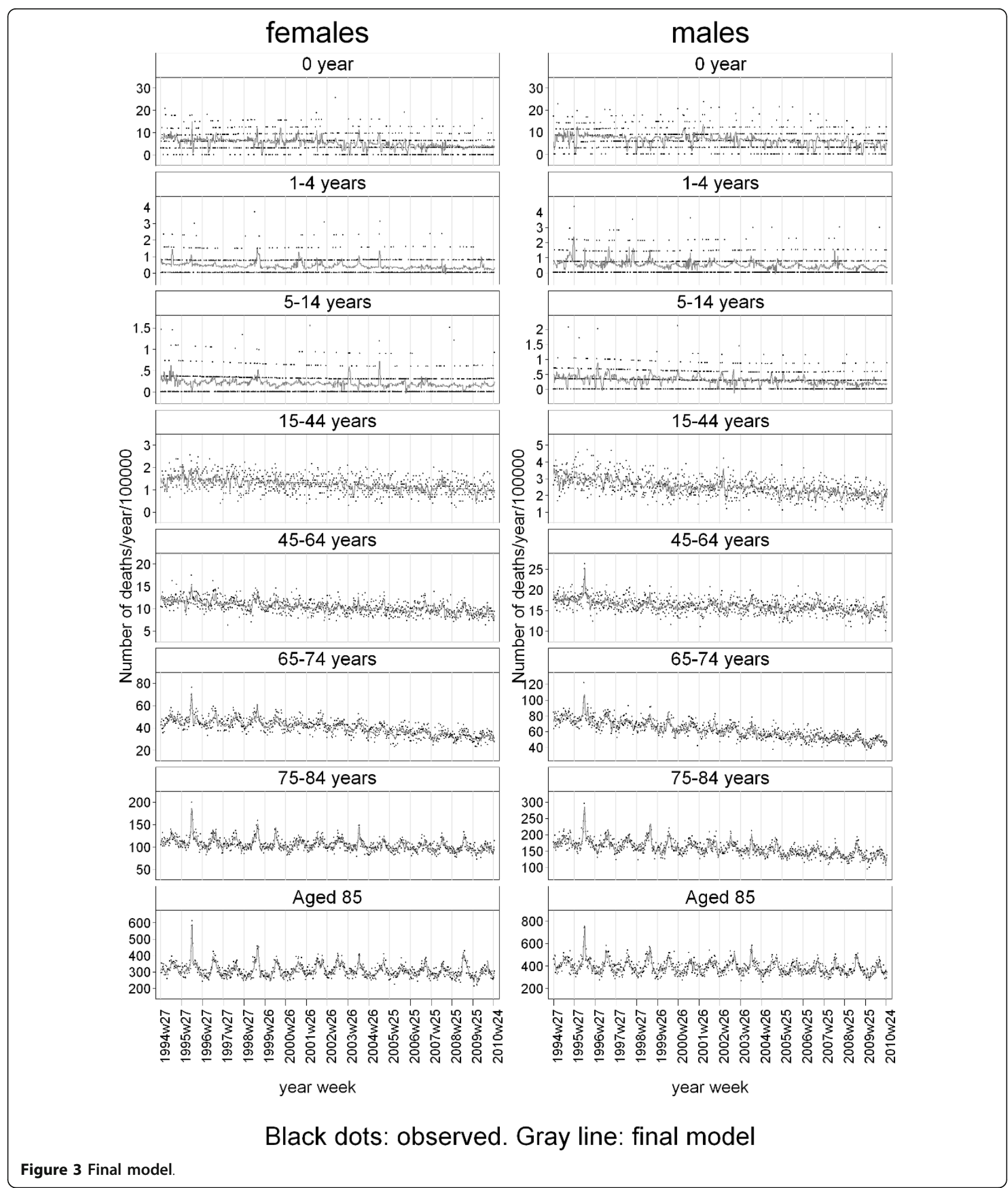

care seeking behaviour (goes earlier to the doctor, stay home) due to knowledge of circulating influenza e.g. from the press.

The median all-cause mortality rate attributable to influenza for Denmark was within the range of estimates from Germany, USA, Italy and Canada based on allcause mortality (Table 6) (range: 10 to 90 deaths per season per 100,000). However, it is important to underline that these estimates were obtained using different models and different periods. 


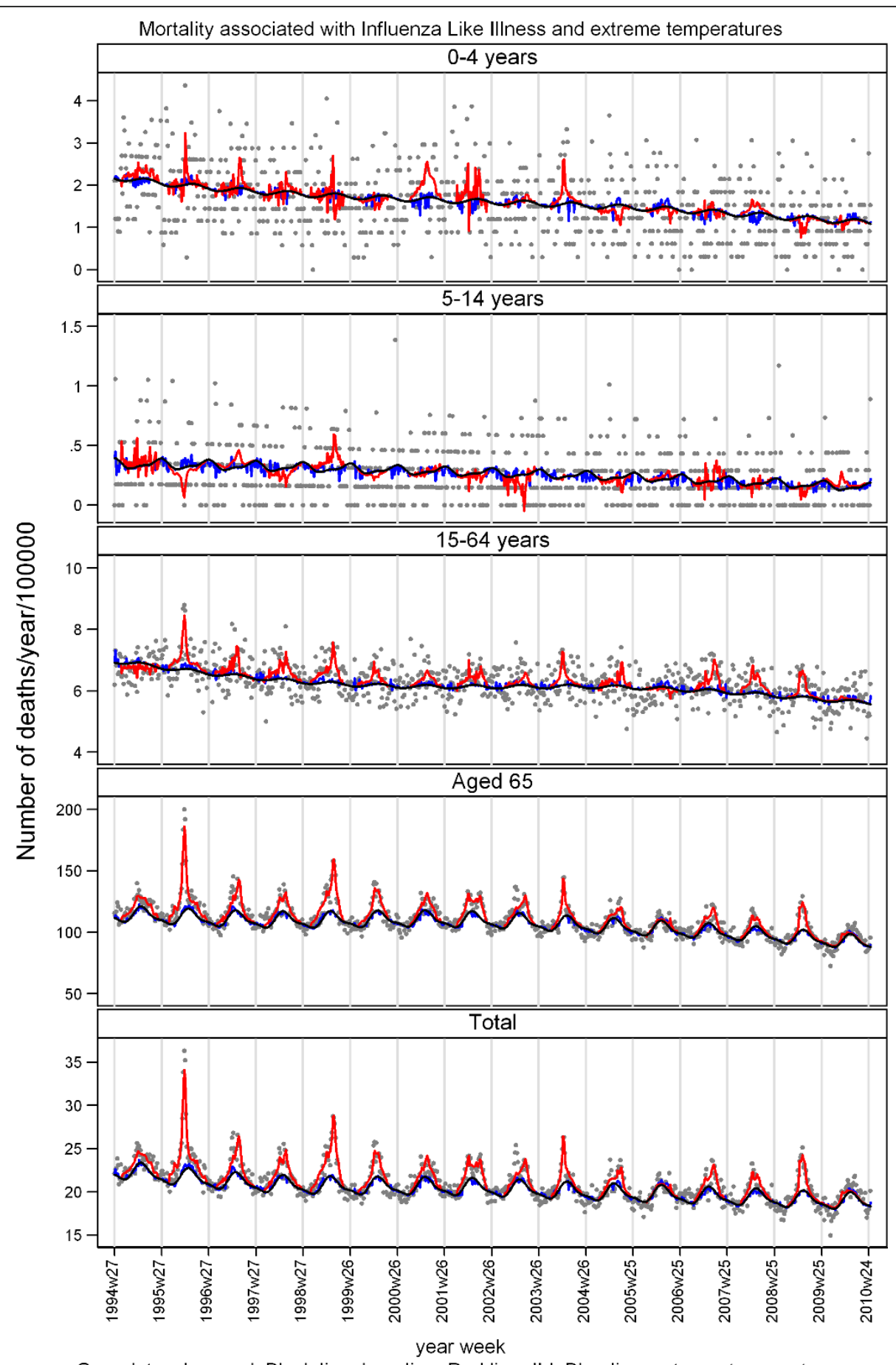

Gray dots: observed. Black line: baseline. Red line: ILI. Blue line: extreme temperatures

Figure 4 Mortality associated with both ILI-activity and extreme temperatures

The most vulnerable age group for influenza death is the elderly with $80-90 \%$ of influenza related deaths among persons aged $65[14,6,25,26,15]$. We estimated the median Danish ILI-attributable mortality rate for persons aged 65 to 206.7 (range: 44.4 to 593.6), corresponding to $88 \%$ of all ILI deaths. Hence, our estimate of the all-cause mortality attributable to circulating influenza for persons aged 65 was within the range of estimates from other countries (table 6).

Surveillance of ILI, will include respiratory infections caused by other pathogens than influenza virus that may be perceived as influenza-like illness. Hence, excess 
Table 2 Excess mortality related to Influenza Like Illness, by season and age group

\begin{tabular}{|c|c|c|c|c|c|c|c|c|c|c|}
\hline Season $^{1}$ & Death & Mortality $^{2}$ & Death & Mortality $^{2}$ & Death & Mortality $^{2}$ & Death & Mortality $^{2}$ & Death & Mortality $^{2}$ \\
\hline Age: & & All ages & & $0-4$ years & & 5-14 years & & 15-64 years & & Aged 65 \\
\hline $1994 / 95$ & 1812 & $34.73(31.80 ; 37.65)$ & 20 & $5.94(2.90 ; 8.99)$ & 7 & $1.21(0.36 ; 2.05)$ & -185 & $-5.26(-6.97 ;-3.54)$ & 1970 & $\begin{array}{c}246.72 \\
(229.23 ; 264.21) \\
\end{array}$ \\
\hline $1995 / 96$ & 5252 & $\begin{array}{c}100.04 \\
(97.22 ; 102.86) \\
\end{array}$ & 10 & $2.88(0.51 ; 5.25)$ & -12 & $\begin{array}{c}-2.16(-2.83 ;- \\
1.49)\end{array}$ & 531 & $\begin{array}{c}15.04 \\
(13.26 ; 16.82) \\
\end{array}$ & 4723 & $\begin{array}{c}593.64 \\
(576.84 ; 610.43) \\
\end{array}$ \\
\hline 1996/97 & 2555 & $48.43(45.69 ; 51.17)$ & 13 & $3.69(1.19 ; 6.20)$ & 10 & $1.64(0.85 ; 2.44)$ & 285 & $8.05(6.22 ; 9.88)$ & 2247 & $\begin{array}{c}283.27 \\
(267.05 ; 299.49) \\
\end{array}$ \\
\hline 1997/98 & 2287 & $43.20(40.65 ; 45.76)$ & 4 & $1.28(-0.89 ; 3.46)$ & -9 & $\begin{array}{c}-1.51(-2.23 ;- \\
0.78)\end{array}$ & 364 & $10.26(8.76 ; 11.76)$ & 1928 & $\begin{array}{c}243.52 \\
(227.85 ; 259.19) \\
\end{array}$ \\
\hline 1998/99 & 4477 & $84.26(81.81 ; 86.71)$ & -3 & $-0.73(-2.95 ; 1.49)$ & 19 & $2.97(2.23 ; 3.71)$ & 478 & $\begin{array}{c}13.43 \\
(12.01 ; 14.85)\end{array}$ & 3983 & $\begin{array}{c}503.84 \\
(488.70 ; 518.98)\end{array}$ \\
\hline 1999/00 & 2125 & $39.87(37.55 ; 42.19)$ & -10 & $\begin{array}{c}-2.99(-5.10 ;- \\
0.88)\end{array}$ & -5 & $\begin{array}{c}-0.73(-1.41 ;- \\
0.05)\end{array}$ & 220 & $6.18(4.63 ; 7.73)$ & 1920 & $\begin{array}{c}242.87 \\
(228.89 ; 256.85)\end{array}$ \\
\hline 2000/01 & 1706 & $31.89(29.19 ; 34.58)$ & 38 & $\begin{array}{c}11.19 \\
(8.58 ; 13.80)\end{array}$ & 1 & $0.11(-0.60 ; 0.81)$ & 220 & $6.17(4.67 ; 7.67)$ & 1447 & $\begin{array}{c}182.75 \\
(165.90 ; 199.61)\end{array}$ \\
\hline $2001 / 02$ & 2615 & $48.71(46.34 ; 51.09)$ & 19 & $5.71(3.43 ; 7.99)$ & -5 & $\begin{array}{c}-0.68(-1.24 ;- \\
0.12)\end{array}$ & 304 & $8.51(7.09 ; 9.93)$ & 2296 & $\begin{array}{c}288.98 \\
(274.30 ; 303.65) \\
\end{array}$ \\
\hline $2002 / 03$ & 1672 & $31.06(28.72 ; 33.41)$ & 3 & $0.98(-1.24 ; 3.21)$ & -13 & $\begin{array}{c}-1.87(-2.45 ;- \\
1.30)\end{array}$ & 159 & $4.45(3.04 ; 5.87)$ & 1523 & $\begin{array}{c}190.66 \\
(176.19 ; 205.12)\end{array}$ \\
\hline $2003 / 04$ & 1946 & $36.05(33.74 ; 38.36)$ & 21 & $6.36(4.00 ; 8.72)$ & 0 & $-0.04(-0.67 ; 0.60)$ & 287 & $8.02(6.65 ; 9.39)$ & 1638 & $\begin{array}{c}203.58 \\
(189.39 ; 217.77)\end{array}$ \\
\hline $2004 / 05$ & 1414 & $26.13(23.60 ; 28.66)$ & -15 & $\begin{array}{c}-4.61(-6.98 ;- \\
2.23)\end{array}$ & -6 & $\begin{array}{c}-0.89(-1.45 ;- \\
0.33)\end{array}$ & 225 & $6.30(4.76 ; 7.83)$ & 1210 & $\begin{array}{c}148.85 \\
(133.49 ; 164.22)\end{array}$ \\
\hline $2005 / 06$ & 306 & $5.63(3.06 ; 8.20)$ & -6 & $-1.72(-3.97 ; 0.53)$ & 5 & $0.74(0.21 ; 1.27)$ & -59 & $-1.65(-3-29 ;-0.01)$ & 365 & $44.35(28.99 ; 59.70)$ \\
\hline $2006 / 07$ & 1718 & $33.37(30.86 ; 35.87)$ & 0 & $0.03(-2.32 ; 2.37)$ & 5 & $0.71(0.09 ; 1.32)$ & 287 & $10.74(9.17 ; 12.32)$ & 1426 & $\begin{array}{c}170.70 \\
(155.89 ; 185.51)\end{array}$ \\
\hline $2007 / 08$ & 1486 & $27.13(24.84 ; 29.42)$ & 14 & $4.16(1.97 ; 6.36)$ & -1 & $-0.13(-0.69 ; 0.44)$ & 397 & $10.98(9.67 ; 12.30)$ & 1076 & $\begin{array}{c}126.12 \\
(112.56 ; 139.69) \\
\end{array}$ \\
\hline $2008 / 09$ & 2113 & $38.35(36.09 ; 40.62)$ & -11 & $\begin{array}{c}-3.42(-5.48 ;- \\
1.35)\end{array}$ & -4 & $\begin{array}{c}-0.65(-1.22 ;- \\
0.08)\end{array}$ & 291 & $8.02(6.76 ; 9.28)$ & 1838 & $\begin{array}{c}209.83 \\
(196.61 ; 223.06) \\
\end{array}$ \\
\hline 2009/10 & 541 & $9.77(7.41 ; 12.14)$ & -3 & $-0.85(-2.79 ; 1.08)$ & 10 & $1.50(0.85 ; 2.15)$ & 55 & $1.50(0.02 ; 2.99)$ & 479 & $53.01(39.84 ; 66.18)$ \\
\hline Median & 1879 & 35.39 & 4 & 1.13 & -1 & -0.08 & 286 & 8.02 & 1738 & 206.71 \\
\hline
\end{tabular}

1) Season: week 27 to week 26 the following year. 2) Deaths per 100,000 per year

mortality attributable to circulating influenza will overestimate mortality associated to influenza. Therefore, PI as cause of death has been used to estimate influenzaassociated mortality $[25,6,4,15,10]$. Using PI-specific mortality has been found to reduce mortality attributable to circulating influenza with $38 \%$ among Swiss elderly (60+) [9], and 40\% for all ages in Canada [27] compared to estimates based on all-cause mortality. However, for various reasons, estimates based on PI as cause of death may tend to under-estimate influenzaassociated mortality. Death due to influenza, or where influenza was an important component in the chain of events that lead to the death, may not be coded as respiratory, but rather as cardiac or related to other complications of severe illness.

We estimated mortality attributable to ILI directly as a parameter in our model. To obtain estimates of influenzaassociated mortality, we could have used data from laboratory based surveillance instead of ILI. However, the virological surveillance of influenza in Denmark is not sufficiently systematic and detailed to be used directly as a parameter to model influenza-associated mortality. Although samples are collected by the sentinel practitioners, they usually collect only three times in a season, which means that the samples do not reflect the amount of circulating influenza, i.e. are not suitable for modelling. Likewise, data on clinical samples from hospitals are, except for the 2009/ 10 pandemic, few in numbers for many seasons. We therefore used a proxy to downgrade ILI to influenza as described above, and estimated an all-cause influenza-associated mortality of 26.4 (range: -0.1 to 72.6 ) per season per 100,000 , corresponding to a $25 \%$ lower mortality compared to ILI-estimates, and slightly higher than PI-associated mortality reported from other countries (table 6). Therefore, with mortality attributable to ILI being an over-estimate and PI-associated mortality probably an underestimate our estimate, using the influenza-index, may well be a realistic estimate of influenza-associated mortality. 
Table 3 Excess mortality associated to Influenza expressed by the influenza-index, by season and age group

\begin{tabular}{|c|c|c|c|c|c|c|c|c|c|c|}
\hline $\operatorname{esson}^{1}$ & eath & 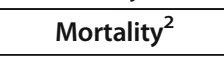 & eath & 2 & Death & $y^{2}$ & Death & 2 & Death & $y^{2}$ \\
\hline ge: & & All ages & & $0-4$ & & 5-14 & & 64 years & & Age \\
\hline $94 / 95$ & 7 & 64) & -1 & 1 1) & 0 & 0) & -233 & $-5.03)$ & & $139.16(122.16 ; 156.16)$ \\
\hline 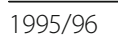 & & & 7 & & - & & 360 & & & \\
\hline 7 & 7 & 2) & 3 & & 7 & 2) & 2 & 9) & 6 & 194.95 \\
\hline $97 / 98$ & 1432 & 27.04 & 0 & 14) & -10 & -1.60 & 276 & 7.77 & 1166 & 62.7 \\
\hline 98/99 & 488 & 65.65 & -11 & -3 & 16 & & 386 & & 3098 & 680 \\
\hline $99 / 00$ & 1802 & & -6 & 201 & -3 & & 158 & ) & נתנון & \\
\hline & 2 & & 21 & & 0 & & 1 & & 931 & \\
\hline 102 & 002 & 52) & 16 & & -2 & 24) & 23 & 83) & 1756 & \\
\hline 103 & & 90) & 3 & 14) & -5 & -0.7 & 122 & 81) & 832 & 14 \\
\hline $03 / 04$ & 1409 & ) & 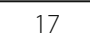 & 47) & 1 & ) & 2 & 5. & 11 & \\
\hline 2004/05 & 988 & 1 & -13 & -3 & -7 & -1 & 1 & 4 & 8 & $105.24(89$. \\
\hline $005 / 06$ & -8 & $-0.14(-2.68 ; 2.40)$ & -6 & ) & 5 & 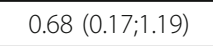 & -67 & 4) & 61 & $7.37(-7.60 ; 22.33)$ \\
\hline $06 / 07$ & 1385 & $25.41(22.93 ; 27.90)$ & 0 & $0.04(-2.32 ; 2.40)$ & 3 & $0.48(-0.17 ; 1.13)$ & 281 & $7.82(6.31 ; 9.33)$ & 1100 & 131.60 \\
\hline $07 / 08$ & 1465 & $26.76(24.51 ; 29.00)$ & 17 & $5.20(3.08 ; 7.31)$ & -1 & $5 ; 0.34)$ & 287 & $9.24)$ & 1162 & 13 \\
\hline 08/09 & 1744 & $31.65(2$ & -10 & $-1.15)$ & -4 & -0.5 & 215 & $7.15)$ & 1543 & 176 \\
\hline 10 & 121 & $2.19(-0.19 ; 4.57)$ & -2 & $-0.64(-2-$ & 8 & 1.83) & -11 & $-0.29(-1$ & 120 & 3;27.29) \\
\hline edian & 1420 & 26.43 & 0 & 0.01 & -1 & -0.12 & 211 & 5.86 & 1164 & 143.11 \\
\hline
\end{tabular}

1) Season: week 27 to week 26 the following year. 2) Deaths per 100,000 per year

Mortality related to influenza has been found to be higher in season where the dominating influenza is H3N2, compared to H1N1 seasons $[5,28,6,7,25]$. We found particular high excess mortality in the two influenza A(H3N2) seasons of 1995/96 and 1998/99, whereas the influenza A(H3N2) season of 2005/6 and the 2009 influenza $\mathrm{A}(\mathrm{H} 1 \mathrm{~N} 1)$ pandemic had none or only modest impact on mortality. In addition, there has been a declining trend in influenza related mortality since the 1990's (Figure 5). This trend remains even after

Table 4 Excess mortality associated to extreme ambient temperatures, by season and age group

\begin{tabular}{|c|c|c|c|c|c|c|c|c|c|c|}
\hline easor & eath & Mort & Death & Mortality $^{2}$ & Death & Mortality $^{2}$ & Death & Mortality $^{2}$ & Death & Morta \\
\hline Age: & & All ages & & $0-4$ years & & 5-14 years & & -64 years & & Aged 65 \\
\hline 5 & 7 & 4) & -1 & -0 & -2 & -( & 50 & 1. & -40 & -5 \\
\hline 0 & 3 & 2) & 5 & ) & 0 & 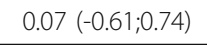 & (5) & 7) & 183 & $2.67)$ \\
\hline 996/97 & 86 & 1.63 & 2 & $0.56(-2.39 ; 3.51)$ & -2 & -0.34 & 70 & $1.99(-0.26 ; 4.24)$ & 16 & $6.46 ; 20.44)$ \\
\hline 997/98 & 117 & $2.22(-0.70 ; 5.13)$ & 1 & $0.21(-2.29 ; 2.71)$ & -1 & $-0.24(-1.09 ; 0.61)$ & 56 & $1.58(-0.17 ; 3.34)$ & 62 & $7.80(-9.98 ; 25.59)$ \\
\hline $98 / 99$ & 112 & 2.28 & 3 & 0. & -1 & -0 & 56 & 21) & 63 & 5.02) \\
\hline 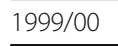 & -17 & 6) & -1 & 2) & -2 & -( & 37 & 7) & -51 & 5) \\
\hline 101 & 62 & 13) & -2 & 53) & -3 & -0 & 46 & .01) & -203 & -2 \\
\hline $01 / 02$ & -139 & -2.58 & -4 & $-1.13(-3.95 ; 1.69)$ & -2 & -0.29 & 32 & $0.90(-0.80 ; 2.59)$ & -165 & $0 ;-4.12)$ \\
\hline $02 / 03$ & 241 & $4.47(1.81 ; 7.14)$ & 4 & $1.13(-1.55 ; 3.81)$ & 0 & $-0.05(-0.69 ; 0.59)$ & 69 & $1.94(0.29 ; 3.60)$ & 167 & ;7.33) \\
\hline 003/04 & 64 & $1.19(-1.30 ; 3.68)$ & 1 & $0.25(-2.53 ; 3.02)$ & -2 & $-0.26(-1.00 ; 0.48)$ & 56 & $1.56(0.09 ; 3.04)$ & 9 & $1.15(-14.18 ; 16.48)$ \\
\hline $04 / 05$ & 1 & $67 ; 3.17)$ & 2 & $2.30 ; 3.34)$ & -3 & -0 & 62 & 3.48) & -47 & -5.7 \\
\hline $2005 / 06$ & 174 & $3.21(0.13 ; 6.29)$ & 4 & $1.25(-1.48 ; 3.97)$ & 0 & $-0.03(-0.65 ; 0.58)$ & 74 & $2.05(0.04 ; 4.07)$ & 97 & $11.77(-6.50 ; 30.04)$ \\
\hline $2006 / 07$ & -135 & $-2.47(-5.32 ; 0.38)$ & -5 & $-1.44(-4.16 ; 1.28)$ & -3 & $-0.39(-1.08 ; 0.30)$ & 50 & $1.39(-0.47 ; 3.25)$ & -177 & $-21.22(-37.93 ;-4.52)$ \\
\hline $2007 / 08$ & -146 & $-2.66(-5.27 ;-0.05)$ & -3 & $-0.89(-3.47 ; 1.68)$ & -3 & $-0.39(-1.04 ; 0.26)$ & 48 & $1.33(-0.17 ; 2.83)$ & -188 & $-22.06(-37.51 ;-6.61)$ \\
\hline $2008 / 00$ & -8 & $-0.14(-2.79 ; 2.50)$ & 0 & $-0.12(-2.60 ; 2.36)$ & -2 & $-0.23(-0.89 ; 043)$ & 32 & $0.89(-0.54 ; 2.33)$ & -38 & $-4.39(-19.91 ; 11.13)$ \\
\hline 009/10 & 164 & $2.97(0.32 ; 5.62)$ & 2 & $0.66(-1.50 ; 2.81)$ & 0 & $0.06(-0.71 ; 0.83)$ & 61 & $1.67(-0.01 ; 3.36)$ & 101 & $11.17(-3.55 ; 25.88)$ \\
\hline Median & 39 & 0.72 & 1 & 0.23 & -2 & -0.27 & 56 & 1.57 & -15 & -1.62 \\
\hline
\end{tabular}


Table 5 Temperature associated mortality differentiated on summer and winter, all ages

\begin{tabular}{|c|c|c|c|c|c|c|c|c|c|c|c|c|}
\hline \multirow[t]{3}{*}{ Season $^{1}$} & \multicolumn{6}{|c|}{ Summer (week 14 to 39 ) } & \multicolumn{6}{|c|}{ Winter (week 40 to 13 ) } \\
\hline & \multicolumn{3}{|c|}{ Cold } & \multicolumn{3}{|c|}{ Warm } & \multicolumn{3}{|c|}{ Cold } & \multicolumn{3}{|c|}{ Warm } \\
\hline & Death & Mortality $^{2}$ & Weeks & Death & Mortality $^{2}$ & Weeks & Death & Mortality $^{2}$ & Weeks & Death & Mortality $^{2}$ & Weeks \\
\hline $94 / 95$ & -30 & $.78 ; 2.62)$ & 7 & 67 & ;4.45) & 5 & 84 & $.56 ; 4.79)$ & 4 & -114 & $-2.19(-5.38 ; 1.00)$ & 15 \\
\hline 1995/96 & -46 & $-0.88(-4.23 ; 2.48)$ & 10 & 44 & $0.84(-2.52 ; 4.19)$ & 6 & 313 & $5.97(2.62 ; 9.33)$ & 17 & -38 & $-0.73(-4.09 ; 2.62)$ & 5 \\
\hline 1996/97 & -79 & $-1.50(-4.74 ; 1.75)$ & 14 & 39 & $0.75(-2.52 ; 4.01)$ & 6 & 199 & $3.78(0.54 ; 7.01)$ & 12 & -74 & $-1.40(-4.66 ; 1.87)$ & 7 \\
\hline 997/98 & -6 & $-0.11(-3.11 ; 2.88)$ & 2 & 94 & $1.78(-1.18 ; 4.74)$ & 11 & 116 & $2.19(-0.78 ; 5.15)$ & 6 & -87 & $-1.64(-4.63 ; 1.35)$ & 7 \\
\hline $98 / 99$ & -65 & $6 ; 1.63)$ & 15 & -2 & -0.03 & 2 & 215 & 4.05 & 11 & -28 & 32) & 5 \\
\hline 1999/00 & -22 & $-0.41(-3.07 ; 2.26)$ & 3 & 72 & $1.36(-1.26 ; 3.98)$ & 9 & 20 & $0.37(2.30 ; 3.04)$ & 2 & -88 & $-1.65(-4.30 ; 1.01)$ & 9 \\
\hline 2000/01 & -87 & $-1.63(-4.84 ; 1.57)$ & 15 & 0 & $0.00(-3.24 ; 3.24)$ & 0 & 86 & $1.61(1.62 ; 4.83)$ & 6 & -160 & $-3.00(-6.20 ; 0.20)$ & 14 \\
\hline $2001 / 02$ & -19 & $-0.35(-3.13 ; 2.43)$ & 6 & 50 & $0.94(-1.83 ; 3.71)$ & 11 & 7 & $0.12(-2.67 ; 2.91)$ & 1 & 177 & $-3.29(-6.03 ;-0.56)$ & 14 \\
\hline $002 / 03$ & -28 & $-0.51(-3.23 ; 2.21)$ & 4 & 62 & $1.15(-1.57 ; 3.87)$ & 9 & 235 & $4.36(1.65 ; 7.07)$ & 15 & -29 & $-0.53(-3.27 ; 2.21)$ & 3 \\
\hline $03 / 04$ & -41 & $-0.76(-3.36 ; 1.84)$ & 6 & 61 & $1.47 ; 3.75)$ & 9 & 124 & $2.30(-0.29 ; 4.89)$ & 8 & -80 & $-1.49(-4.06 ; 1.09)$ & 6 \\
\hline $2004 / 05$ & -105 & $-1.95(-4.91 ; 1.02)$ & 15 & 20 & $0.37(-2.64 ; 3.38)$ & 3 & 154 & $2.84(-0.15 ; 5.84)$ & 9 & -55 & $-1.01(-4.01 ; 1.98)$ & 3 \\
\hline 2005/06 & -82 & $-1.51(-4.60 ; 1.58)$ & 12 & 0 & $0.00(-3.11 ; 3.11)$ & 0 & 286 & $5.27(2.17 ; 8.37)$ & 14 & -30 & $-0.55(-3.65 ; 2.56)$ & 3 \\
\hline 2006/07 & -10 & $-0.18(-3.11 ; 2.76)$ & 1 & 107 & $1.97(-0.91 ; 4.85)$ & 15 & 0 & $0.00(-2.94 ; 2.94)$ & 0 & -232 & $-4.26(-7.18 ;-1.35)$ & 17 \\
\hline $007 / 08$ & -62 & $-1.14(-3.78 ; 1.51)$ & 12 & 23 & $0.41(-2.25 ; 3.02)$ & 5 & 83 & $1.51(-1.15 ; 4.17)$ & 7 & -189 & $-3.45(-6.11 ;-0.79)$ & 15 \\
\hline $008 / 09$ & -28 & $-0.51(-3.21 ; 2.18)$ & 7 & 38 & $0.70(-1.98 ; 3.38)$ & 6 & 53 & $0.96(-1.73 ; 3.65)$ & 4 & -71 & $-1.30(-3.99 ; 1.40)$ & 10 \\
\hline 009/10 & -22 & $-0.40(-3.10 ; 2.30)$ & 7 & 56 & $1.02(-1.67 ; 3.70)$ & 9 & 179 & $3.23(0.05 ; 5.91)$ & 11 & -49 & $-0.88(-3.58 ; 1.83)$ & 6 \\
\hline ledian & -36 & -0.67 & 7 & 47 & 0.89 & 6 & 119 & 2.24 & 8 & -77 & -1 & 7 \\
\hline
\end{tabular}

1) Season: week 27 to week 26 the following year. 2) Deaths per 100,000 per year

Table 6 Mortality related to influenza

\begin{tabular}{|c|c|c|c|c|c|}
\hline Country & Period & Age group & Mortality per 100,000 & Method & Reference \\
\hline $\begin{array}{l}\text { West Germany } \\
\text { Germany }\end{array}$ & $\begin{array}{l}1984 / 85-1994 / 95 \\
1990 / 91-2000 / 01 \\
\end{array}$ & All & $\begin{array}{l}16.1 \text { (range: } 2.2 ; 35.7 \text { ) } \\
17.4 \text { (range: } 5.9 ; 44.2 \text { ) }\end{array}$ & All cause & Zucs 2005 [28] \\
\hline$\overline{U S A}$ & 1972/73-2002/03 & All & $\begin{array}{l}65.0 \text { (range: 0;134.2) } \\
72.4 \text { (range 11.7;144.7) }\end{array}$ & All cause & Thompson 2009 [3] \\
\hline Canada & $\begin{array}{l}1997-2000 \\
2000-2004\end{array}$ & All & $\begin{array}{l}15,6 \\
5.8 \text { (vaccination) }\end{array}$ & All cause & Kwong 2008 [12] \\
\hline Italy & 1969-2001 & All & $23.4(\mathrm{H} 3 \mathrm{~N} 2) / 7.4(\mathrm{H} 1 \mathrm{~N} 1)$ & All cause & Rizzo 2007 [6] \\
\hline Canada & 1989/90-1998/99 & All & 13.1 & All cause & Schanzer 2007 [27] \\
\hline $\begin{array}{l}\text { South Africa } \\
\text { USA }\end{array}$ & $\begin{array}{l}1998-2005 \\
1997 / 98-2004 / 05\end{array}$ & $65+$ & $\begin{array}{l}340 \\
112\end{array}$ & All cause & Cohen 2010 [7] \\
\hline Czech Republic & 1982/83-1999/00 & $65+$ & 26.0 (range: $-8.9 ; 60.4$ ) & All cause & Kyncl 2005 [30] \\
\hline Netherlands & $\begin{array}{l}1992-1996 \\
1996-2003 \\
\end{array}$ & $65+$ & $\begin{array}{l}131 \text { (95\% Cl: 123-139) } \\
105 \text { (95\% Cl: 99-111) (vaccination) }\end{array}$ & All cause & Jansen 2008 [31] \\
\hline Hong Kong & 1996-1999 & $65+$ & $\begin{array}{l}93.2 \text { (95\% Cl: 78.4-107.7) } \\
136.1 \text { (95\% Cl: 83.7-188.4) }\end{array}$ & All cause & Wong 2004 [15] \\
\hline Portugal & 2008/09 & $65+$ & 18 & All cause & Nogueira 2009 [8] \\
\hline Switzerland & $\begin{array}{l}1969 / 70-1998 / 99 \\
1988 / 89-1998 / 99\end{array}$ & $60+$ & $\begin{array}{l}67.2 \text { (range: } 20.9 ; 209,5) \\
152.8 \text { (range: } 66.3 ; 293.3 \text { ) } \\
69.5 \text { (range: } 32.6 ; 234,5 \text { ) } \\
187.1 \text { (range: } 121.0 ; 356.0 \text { ) } \\
115.3 \text { (range: } 60.6 ; 226.9 \text { ) }\end{array}$ & All cause & Brinkhof 2006 [9] \\
\hline Netherlands & 1967-1989 & $60+$ & 82 & All cause & Sprenger 1993 [32] \\
\hline USA & 1976/77-2006/07 & All & $\begin{array}{l}9.0 \text { (range: } 1.4 ; 16.7 \text { ) } \\
2.4 \text { (range: } 0.4 ; 5.1 \text { ) }\end{array}$ & $\begin{array}{l}\mathrm{RC} \\
\mathrm{Pl}\end{array}$ & MMWR 2010 [25] \\
\hline Italy & $1969-2001$ & All & $4.5(\mathrm{H} 3 \mathrm{~N} 2) / 0.8(\mathrm{H} 1 \mathrm{~N} 1)$ & $\mathrm{Pl}$ & Rizzo 2007 [6] \\
\hline $\begin{array}{l}\text { USA } \\
\text { France } \\
\text { Australia }\end{array}$ & 1972-1997 & All & $\begin{array}{l}2.6 \text { (range: } 0 ; 6.3 \text { ) } \\
3.9 \text { (range: } 0 ; 18.3 \text { ) } \\
1.3 \text { (range: } 0 ; 7.5 \text { ) }\end{array}$ & $\mathrm{Pl}$ & Viboud 2004 [4] \\
\hline
\end{tabular}


Table 6 Mortality related to influenza (Continued)

\begin{tabular}{|c|c|c|c|c|c|}
\hline $\begin{array}{l}\text { South Africa } \\
\text { USA }\end{array}$ & $\begin{array}{l}1998-2005 \\
1997 / 98-2004 / 05\end{array}$ & $65+$ & $\begin{array}{l}42 \\
22\end{array}$ & $\mathrm{Pl}$ & Cohen 2010 [7] \\
\hline Hong Kong & 1996-1999 & $65+$ & $\begin{array}{l}16.7 \text { (95\% Cl: } 9.8-23.7) \\
39.3 \text { (95\% Cl: } 21.4-57.3)\end{array}$ & $\mathrm{Pl}$ & Wong 2004 [15] \\
\hline France & 1984-2004 & $65+$ & 1.4 (range: 0;9.4) & $\mathrm{Pl}$ & Denoeud 2007 [10] \\
\hline
\end{tabular}

RC: Respiratory and circulatory cause's incl. pneumonia and influenza. Vaccination: After introduction of vaccination programme

excluding the low-mortality 2005/6 H3N2 season and the 2009/10 H1N1 pandemic, although not that strong. The reasons for this trend are not obvious, but increased use of vaccines for the elderly, genetic drift of the virus as well as herd immunity in the population may contribute.

Over the seasons $1994 / 5$ to $2009 / 10$ we found an allcause median mortality rate of 0.7 (range: -3.0 to 5.2 ) per season per 100,000 attributable to periods with extreme temperatures for all ages and all inhabitants in Denmark, adjusted for trend, seasonality, influenza activity and heterogeneities between age groups and genders. However, this consists of both periods with extreme cold and heat, and covers both summer and winter. Perhaps not surprisingly, there seems to be a pattern where periods with cold weather in the summer is life saving, while heat may cost lives. In the winter season warm periods saves lives, while cold cost lives.

We have proposed and evaluated a methodology and statistical model usable to estimate excess mortality associated to two potential explanatory factors, ILI and extreme temperatures based on all-cause mortality. The model fitted data well and all-cause mortality has previously been found to be the most complete and accurate in assessing the total impact of influenza on mortality [29]. More explanatory factors may be included in the model like for example infection with RSV [11], other cause of acute respiratory illnesses and invasive pneumococcal disease, to get more detailed estimates of variations in excess mortality. A limitation of the model is potential interactions between the explanatory factors, which cannot be easily implemented in the model; especially with more

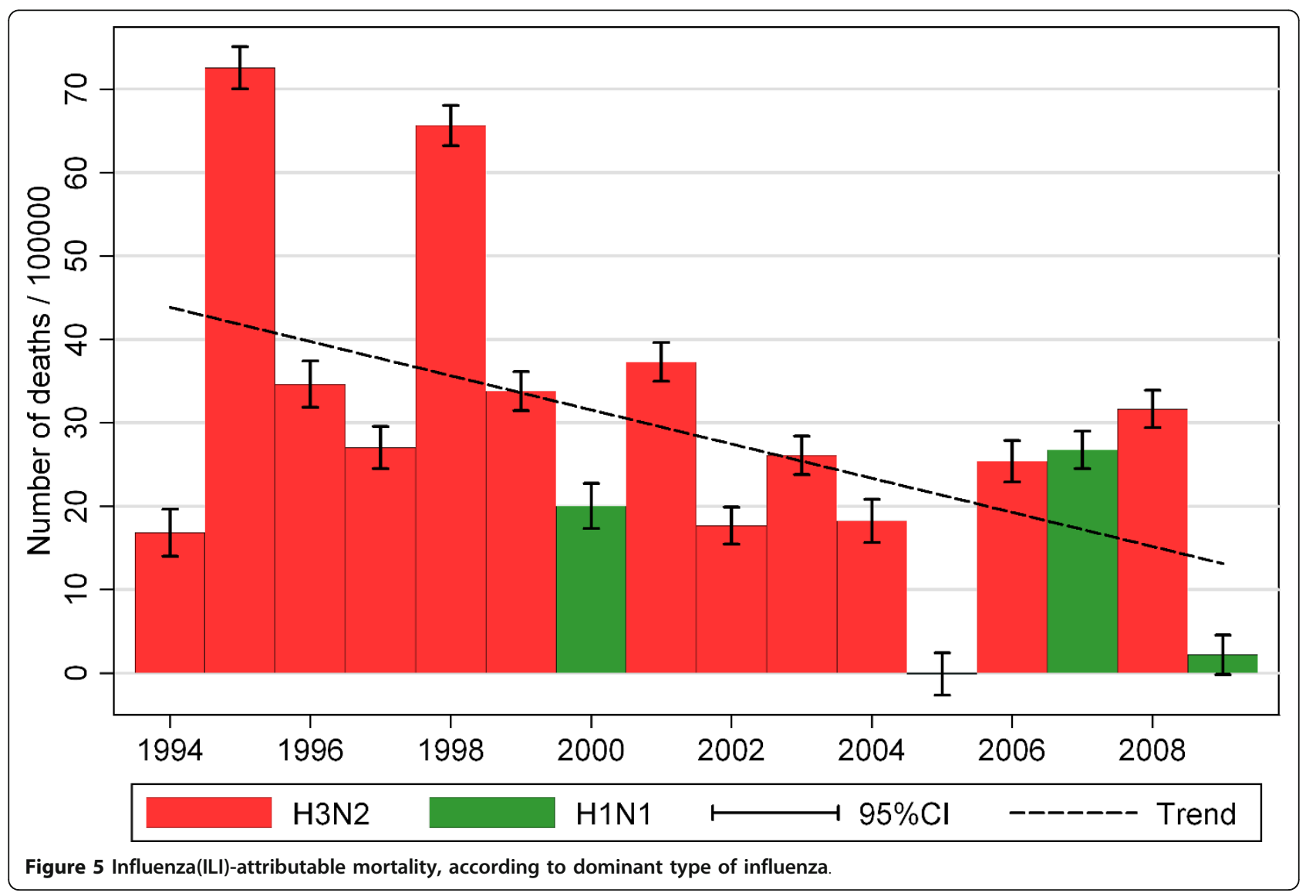


than two explanatory factors. As influenza virus circulates simultaneously with other respiratory infections, ILI may include infections caused by other pathogens than influenza virus and may as such be an overestimation of circulating influenza. Denmark does not have systematic ongoing laboratory surveillance of influenza, but among influenza-samples received at the reference laboratory at Statens Serum Institut, the proportion of influenza positive samples is typically low in the beginning and end of the season, and highest around the peak of ILI. Our influenzaindex reflects this pattern Others have used PI cause-specific mortality as outcome, and our methodology gives influenza-associated mortality that falls between the overestimation using all cause mortality and the under-estimation using PI cause specific mortality. Further, it has the advantage of depending only on easily obtainable data namely weekly number of all-cause deaths, temperature, and ILI.

\section{Conclusions}

We have shown that it is doable to model seasonally fluctuations in mortality related to ILI or influenza and to extreme ambient temperatures based on all-cause mortality. This is promising, as all-cause data is easier to obtain than cause-specific data, and not subject to coding bias. It is recognised that coding practices will be affected by awareness and media reports. However, it is of interest to apply our methodology to other datasets in order to validate it further. We also advocate that laboratory based influenza surveillance should be reinforced in order to better estimate the proportion of severe respiratory illness that are caused by influenza. This may serve as a more appropriate independent variable in future multivariable models. Finally, it is worth noting that influenza mortality has tended to decline and studies of the effect of in particular influenza vaccination policies on this trend are needed.

\section{Acknowledgements}

This is part of the EuroMOMO project funded by the European Commission (DG SANCO grant 20072001). Neither the European Commission nor any person acting on its behalf is liable for any use made of the information published here.

\section{Authors' contributions}

JN did the data analyses and was the lead writer. AM, SG and KM wrote part of introduction and discussion, and contributed with ideas and comments to methods and results. All authors read and approved the final manuscript.

\section{Competing interests}

The authors declare that they have no competing interests.

Received: 8 June 2011 Accepted: 16 December 2011 Published: 16 December 2011

\section{References}

1. Philips D, Barker GE, Brewer KM: Christmas and New Year as risk factors for deaths. Social Science \& Medicine 2010, 17:1463-71.
2. Serfling RE: Methods for current statistical analysis of excess pneumoniainfluenza deaths. Public Health Rep 1963, 78:494-506.

3. Thormpson WW, Weintraub E, Dhankhar P, Cheng PY, Brammer L, Meltzer MI, Bresee JS, Shay DK: Estimates of US influenza-associated deaths made using four different methods. Influenza and Other Respiratory Viruses 2009, 3:37-49.

4. Viboud C, Boelle PY, Pakdaman K, Carrat F, Valleron AJ, Flahault A: Influenza epidemics in the United States, France, and Australia, 1972-1997. Emerging Infectious Diseases 2004, 10 [http://www.cdc.gov/eid], No. 1.

5. Simonsen L, Reichert TA, Viboud C, Blackwelder W, Taylor RJ, Miller MA: Impact of influenza vaccination on seasonal mortality in the US elderly population. Arch Intern Med; 2005:165:265-72.

6. Rizzo C, Bella A, Viboud C, Simonsen L, Mille MA, Rota MC, Salmaso S, Atti MLCd: Trends for influenza-related deaths during pandemic and epidemic seasons, Italy, 1969-2001. Emerging Infectious Diseases 2007, 13 [http://www.cdc.gov/eid], No. 5.

7. Cohen C, Simonsen L, Kang JW, Miller M, McAnerney J, Blumberg L, Schoub B, Madhi SA, Viboud C: Elevated influenza-related excess mortality in South Africa elderly individuals, 1998-2005. Clinical Infectious Diseases 2010, 51:1362-69.

8. Nogueira PJ, Nunes B, Machado A, Rodrigues E, Gomez V, Sousa L, Falcao JM: Early estimates of the excess mortality associated with the 2008-9 influenza season in Portugal. EuroSurveillance; 200914(18), pii = 19194.

9. Brinkhof MGW, Spoerri A, Birrer A, Hagman R, Koch D, Zwahlen M: Influenza-attributable mortality among elderly in Switzerland. Swiss Medical Weekly 2006, 136:302-309.

10. Denoeud L, Turbelin C, Ansat A, Valleron AJ, Flahault A, Carrat F: Predicting pneumonia and influenza mortality from morbidity data. PLOS 2007, 5: e464.

11. Newall AT, Viboud C, Wood JG: Influenza-attributable mortality in Australians aged more than 50 years: a comparison of different modeling approaches. Epidemiol Infect 2010, 138:836-42.

12. Kwong JC, Stukel TA, Lim J, McGeer AJ, Upshur REG, Johansen H, Sambell C, Thompson WW, Thiruchelvam D, Marra F, Svenson LW, Manuel DG: The effect of universal influenza immunization on mortality and health care use. PLOS Medicine 2008, 5(10):e211.

13. Farrington $C P$, Andrews NJ, Beal AD, Catchpole MA: A statistaical algorithm for the early detection of outbreaks of infectious diseases. J R Statist Soc 1996, 159:547-63.

14. Tillett HE, Smith JWG, Clifford RE: Excess morbidity and mortality associated with influenza in England and Wales. Lancet 1989, 783-5.

15. Wong CM, Chan KP, Hedley AJ, Peiris JSM: Influenza-associated mortality in Hong Kong. Clinical Infectious Diseases 2004, 39:1611-7.

16. Diaz J, Linarees C, Tobias A: Impact of extreme temperatures on dayly mortality in Madrid (Spain) among the 45-64 age-group. Int J Biometeorol 2006, 50:342-48.

17. Yang TC, Wu PC, Chen VYJ, Su HJ: Cold surge: A sudden and spatially threat to health? Science of the total environment 2009, 407:3421-24.

18. Revich BA, Shaposhnikov DA: Extreme temperature episodes and mortality in Yakutsk, East Siberia. Rural and Remote Health 2010, 10:1338

19. Joacim R, Kristie E, Bertil F: Mortality related to temperature and persistent extreme temperatures: a study of cause-specific and agestratified mortality. Occup Environ Med 2011, 68(7):531-6.

20. NOAA: National Oceanic and Atmospheric Administration. http://www. ncdc.noaa.gov/oa/climate/climatedata.html\#daily (accessed 13/12/2011).

21. Armstrong BG, Chalabi Z, Fenn B, Hajat S, Kovats S, Milojevic A, Wilkinson P: Association of mortality with high temperatures in a temperate climate: Endland and wales. J Epidemiol Community Health 2011, 64:340-5.

22. StatBank. Statistics Denmark. http://www.statistikbanken.dk/statbank5a/ default.asp? W=1280 (accessed 13/12/2011).

23. van den Wijngaard CC, van Asten L, Meijer A, van Pelt W, Nagelkerke NJD, Donker GA, van der Sande MAB, Koopmans MPG: Detection of excess influenza severity: associating respiratory hospitalization and mortality data with reports of influenza-like-illness by primary care physicians. American Journal of Public Health 2010, 100:2248-2254.

24. McCullagh P, Nelder JA: Generalized Linear Models. London: Chapman \& Halli, 2 1989.

25. MMWR: Estimates of deaths associated with seasonal influenza - United States, 1976-2007. Morbidity and Mortality Weekly Report 2010, 59, No. 33 www.cdc.gov/mmwr. 
26. Shindo N: Morbidity and mortality of influenza in Japan. Nippon Rinsho 2000, 11:2187-91, [article in Japanese].

27. Schanzer DL, Tam TWS, Langley JM, Winchester BT: Influneza-attributable deaths, Canada 1990-1999. Epidemiology of Infections 2007, 135:1109-1116.

28. Zucs P, Buchholz U, Haas W, Uphoff H: Influenza associated excess mortality in Germany 1985-2001. Emerging Themes in Epidemiology 2005, 2:6.

29. Simonsen L, Clark MJ, Williamson GD, Stroup DF, Arden NH, Schoenberger LB: The impact of influenza epidemics on mortality: introducing a severity index. Am J Publ Health 1997, 87:1944-50.

30. Kyncl J, Prochazka B, Goddard NL, Havlickova M, Castkova J, Otavova M, Kriz B: A study of excess mortality during influenza epidemics in the Czech Republic 1982-2000. European Journal of Epidemiology 2005, 20:365-371.

31. Jansen AGSC, Sanders EAM, Nicol KL, van Loon AM, Hoes AW, Hak E: Decline in influenza-associated mortality among Dutch elderly following the introduction of a nationwide vaccination program. Vaccine 2008, 26:5567-5574.

32. Sprenger MJW, Mulder PGH, Beyer WEP, Strik RV, Masurel N: Impact of influneza on mortality in relation to age ande underlying disease, 19671989. International Journal of Epidemiology 1993, 22:334-340.

\section{Pre-publication history}

The pre-publication history for this paper can be accessed here: http://www.biomedcentral.com/1471-2334/11/350/prepub

doi:10.1186/1471-2334-11-350

Cite this article as: Nielsen et al:: Excess mortality related to seasonal influenza and extreme temperatures in Denmark, 1994-2010. BMC Infectious Diseases 2011 11:350.

\section{Submit your next manuscript to BioMed Central} and take full advantage of:

- Convenient online submission

- Thorough peer review

- No space constraints or color figure charges

- Immediate publication on acceptance

- Inclusion in PubMed, CAS, Scopus and Google Scholar

- Research which is freely available for redistribution

Submit your manuscript at www.biomedcentral.com/submit 